\title{
NARRATIVA, NARRATIVAS E PONTO DE VISTA: ANOTAÇÕES PARA UM ENSINO EXPLÍCITO DA LITERATURA
}

\author{
NARRATIVE, NARRATIVES AND POINT OF VIEW: NOTES FOR AN \\ EXPLICIT TEACHING OF LITERATURE
}

\author{
Philio Generino TERZAKIS*
}

\begin{abstract}
Resumo: Este artigo tem como objetivo apresentar uma proposta de aula de literatura baseada na metodologia do ensino explícito, como forma de proporcionar um aprendizado mais efetivo para alunos do curso de Letras Estrangeiras Modernas com dificuldades de leitura e escrita, e pouca prática de leitura de textos literários. Inicialmente nossa proposta se dirige ao ensino universitário, mas o ensino explícito também pode ser adotado em todos os níveis de ensino, tendo apresentado resultados positivos para crianças, jovens e adultos, principalmente aqueles com dificuldades de aprendizado, como demonstram os trabalhos recentes de Steve Bissonnette, Clermont Gauthier e outros pesquisadores. Focada no professor, essa metodologia não depende de mudanças drásticas na escola nem de investimentos adicionais. Fundamentado nas descobertas da psicologia cognitiva, realizadas desde os anos 50 do século passado, o ensino explícito pode ser uma resposta para as limitações do aluno brasileiro no domínio da leitura, evidenciadas pelos resultados mais recentes do Programa Internacional de Avaliação de Estudantes (Pisa), parte dos quais apresentamos neste artigo. Como forma de contextualizar nossa situação atual em matéria de ensino de literatura, traçamos também neste artigo um breve histórico da história da educação ocidental, bem como do lugar da literatura nas escolas desde a Antiguidade Clássica. Em uma segunda parte, nos dedicamos a apresentar a primeira etapa do que seria uma aula fundamentada metodologicamente no ensino explícito, qual seja, a fase de preparação, com destaque para a apropriação do conteúdo necessário (teorias do ponto de vista) e um breve roteiro da aula, com a proposta de atividades que respeitem a memória de trabalho do aprendiz. Como forma de desenvolvimento do senso crítico do aluno, também propomos relacionar o estudo do assunto da aula proposta (o conto "A casa de Astérion", de Jorge Luis Borges, e a categoria narrativa do ponto de vista) e a noção de narrativa, da maneira como ela vem sendo difundida nas redes sociais, aproximando assim o estudo da literatura e a vivência cotidiana dos alunos.
\end{abstract}

Palavras-chave: Ensino explícito. Metodologia. Literatura. Narrativa. Ponto de vista.

Abstract: This paper presents a proposal to teach literature based on explicit teaching as a way to
provide more effective learning for modern foreign languages students who have difficulties in reading
and writing as well as little practice in reading literary texts. Initially, the proposal is aimed at college
education, but it can also be adopted at all levels. It has shown positive results for children, youth and
adults, especially for those with learning difficulties, as demonstrated by recent works of Steve
Bissonnette, Clermont Gauthier and other researchers. Focused on the teacher, it does not depend on
great changes in school environments or any additional investments. Based on the discoveries of
cognitive psychology made since the 1950s, it can be an answer to Brazilian students' limitations in the
field of reading, which were evidenced by the most recent results of the Program for International
Student Assessment (Pisa), part of which is presented in this paper. The paper is divided in two parts.
The first one presents a contextualization of the current situation of the teaching of literature, by tracing
a brief history of Western education, as well as of the place of literature in schools since Classical
Antiquity. In the second part, it presents the first stage of what a class based on explicit teaching would
be like. It presents the preparation phase, with emphasis on the appropriation of the necessary content
(theories of point of view), as well as a brief script of a class, which includes activities that respect

* Professora da Universidade Federal da Paraíba (UFPB). Doutorado em Letras pela UFPB. E-mail: philiogt@gmail.com.

Revista Graphos, vol. 22, n 2, 2020 | UFPB/PPGL | ISSN 1516-1536 
learners' working memory. As a way of developing students' critical sense, students are encouraged to relate the class content (the short story "The house of Astérion", by Jorge Luis Borges, and the narrative category of point of view) to the popular notion of narrative in the way it has been disseminated in social media, thus bringing the study of literature and the students' daily experience closer together.

Keywords: Explicit teaching. Method. Literature. Narrative. Point of view.

\section{Introdução}

“Professora, o que a senhora quer que a gente diga?" Essa foi a pergunta feita por um dos alunos mais corajosos durante um debate sobre o conto "A casa de Astérion", de Jorge Luis Borges, em uma aula de teoria literária, no curso de Letras Estrangeiras Modernas da Universidade Federal da Paraíba (UFPB). Essa e outras situações podem e devem nos abrir os olhos a respeito da necessidade urgente de repensarmos a metodologia de ensino superior - em particular do ensino de leitura e escrita, habilidades estas essenciais para o pleno exercício da cidadania e imensamente dependentes da prática de leitura do texto de ficção. De imediato, o que se torna evidente é a distância entre nós, professores pesquisadores/leitores experientes de literatura e alunos que, não poucas vezes, conseguem, sim, chegar à universidade com sérias dificuldades para ler e escrever de modo proficiente.

A busca por uma metodologia mais eficiente nos levou ao ensino explícito ${ }^{1}$, que hoje nos parece uma das propostas mais promissoras para a renovação da maneira de ensinar não apenas a literatura, mas outras disciplinas, e não apenas na escola, mas também nas universidades. A seu favor, o ensino explícito tem, entre outras qualidades, a capacidade de harmonizar, sem maniqueísmo e demonização, as duas vertentes metodológicas mais conhecidas atualmente: a pedagogia tradicional e a pedagogia nova - esta última mais conhecida por meio da difusão do ensino construtivista.

Neste artigo, apresentamos uma proposta de aula de teoria literária, a partir da metodologia do ensino explícito, sobre o conto "A casa de Astérion”, de Jorge Luis Borges, e a categoria narrativa do ponto de vista. Este texto divide-se em duas partes. Na primeira parte, apresentamos: a) um brevíssimo resumo da história da educação ocidental e da literatura; b) os resultados mais recentes do Programa Internacional de Avaliação de Estudantes (Pisa) referentes ao nível de leitura dos estudantes brasileiros; c) e os principais conceitos e etapas do

\footnotetext{
${ }^{1}$ Nesse contexto, o ensino é considerado explícito por sua abordagem instrucionista, que fornece uma orientação direta para os alunos, por meio do dizer e do mostrar, em oposição à pedagogia da descoberta, que, não raramente, exige do aprendiz uma autonomia da qual ele ainda não é capaz, prejudicando seu aprendizado (GAUTHIER, 2018).
} 
ensino explícito. A segunda parte contém: a) uma revisão das teorias mais relevantes do ponto de vista; b) um comentário sobre a difusão do termo "narrativa" no cotidiano; c) e a proposta de aula propriamente dita. O objetivo da primeira parte é fornecer um panorama no qual possam ser inseridas não apenas a situação atual dos nossos estudantes, como a proposta do ensino explícito. Já a segunda parte apresenta a primeira etapa do modelo PIC do ensino explícito (Preparação - Interação - Consolidação).

\section{Primeira parte}

Educação ocidental e ensino da literatura: alguns elementos

As raízes da história ocidental costumam ser localizadas na Antiguidade Clássica, pois lá teria surgido um tipo de pensamento racional em contraposição ao pensamento mítico-religioso. Esse período marcaria, portanto, não apenas o surgimento da literatura ocidental, mas também da teoria da literatura e do ensino da literatura. É na mesma época que se encontra a origem da nossa escola (CAMBI, 1999).

A literatura já era objeto de estudo nas escolas gregas clássicas, que podiam ser estatais ou particulares. As escolas romanas, por sua vez, adotaram o modelo das escolas gregas a partir do século II a.C; este seria exportado para todo o Império e formaria uma das bases da Europa, juntamente com a cultura cristã. Essas escolas eram direcionadas às camadas superiores da sociedade, visando à formação idealizada do homem universal e a participação social por meio da palavra (CAMBI, 1999) - nas classes mais baixas, a educação era voltada para o trabalho manual. Não podemos esquecer, entretanto, que desde então o conceito e o uso da literatura se transformaram. As obras de Homero, por exemplo, não eram simplesmente literárias, como hoje, conforme explica Otto Maria Carpeaux (2008, p. 178-9):

\footnotetext{
$\mathrm{Na}$ Antiguidade também, assim como nos tempos modernos, Homero era indiscutido: mas não como epopeia, e sim como Bíblia. Era um Código. Versos de Homero serviam para apoiar opiniões literárias, teses filosóficas, sentimentos religiosos, sentenças dos tribunais, moções políticas. Versos de Homero citaram-se nos discursos dos advogados e estadistas, como argumentos irrefutáveis. "Homero": isto significava a "tradição", no sentido em que a Igreja Romana emprega a palavra, como norma de interpretação da doutrina e da vida.
}

Para se ter uma ideia da importância de Homero na formação dos cidadãos gregos, até mesmo em Esparta, cidade-estado cuja educação tinha como objetivo precípuo a formação militar, e não ler e escrever, como em Atenas, os alunos eram obrigados a aprender Homero de cor. A Idade Média vai rejeitar essa cultura pagã e revisá-la de acordo com a visão cristã. Nas 
escolas medievais, dirigidas pela Igreja, os textos religiosos em latim eram o grande objeto de estudo, e não os literários. O ideal de formação não era mais o homem universal, e sim o homem cristão, imitação da figura do Cristo. Uma coisa não muda: a educação técnica ainda é reservada para o povo que, ao contrário do que ocorre na Antiguidade, não aprende nem mesmo a ler. Segundo Cambi, essa oposição entre o trabalho intelectual, para os ricos, e o trabalho manual, para os pobres, será uma das heranças da Grécia Clássica até hoje.

Tanto na Antiguidade Clássica quanto na Idade Média, a infância será muito pouco valorizada. O sentimento da infância só começará a surgir na Idade Moderna, durante a qual também assistimos ao esboço da nossa escola com a sistematização do ensino e o surgimento da pedagogia como ciência. Nessa época, o Estado nacional está no centro do poder e o exerce também sobre a educação, por meio do ensino público e estatal. A família torna-se, mais e mais, um local de educação e não apenas um núcleo econômico. O ideal de formação é o cortesão (cultura ornamental) e, em seguida, o homem cidadão. Com esse objetivo, as escolas tornamse cada vez mais ideológicas. De acordo com Cambi, a simbiose entre política e educação é uma das características da Idade Moderna e vai se acentuar depois da Revolução Francesa, permanecendo até hoje um dos traços principais da nossa escola.

Quanto ao ensino da literatura, com o Renascimento e o Humanismo, os textos clássicos voltam a ocupar um local de destaque nas escolas. Apesar da inspiração clássica, o ensino moderno da literatura é bem mais pobre, focando em questões formais retóricas e gramaticais. Afinal, a cultura da palavra não está mais no centro de interesses da época, que se amplia para incluir as questões religiosas (Reforma e Contrarreforma), políticas (democracia) e científicas (matemática e ciência experimental). O latim e o grego também sofrem a concorrência das línguas e das literaturas nacionais.

Depois da Revolução Francesa (1789), a educação se difunde e a escola torna-se mais e mais central. Afinal, os agora eleitores precisam saber ler e escrever para participar dos processos democráticos. Os pais levam as crianças para o professor cada vez mais cedo, não raro obrigados pela Lei. O Estado passa a dominar de modo crescente as escolas públicas e privadas. A partir do século XIX, o foco da educação se dividirá entre o positivismo (ciência) e o marxismo (trabalho e instrução ${ }^{2}$ ). A formação clássica do homem universal sai definitivamente de moda, sendo substituída pela do homem histórico, o cidadão, preocupado

\footnotetext{
${ }^{2}$ No século XIX, surgem as escolas técnicas, mostrando que o trabalho estava no foco do sistema de educação da época: o homem era educado para as fábricas. Conforme as décadas avançam, a instrução ganha importância, em detrimento do trabalho (CAMBI, 1999). É dessa dicotomia que surge a polêmica ainda atual sobre a necessidade ou não de os cursos das universidades refletirem as exigências do mercado de trabalho.
} 
com as necessidades da sociedade e com as ideologias. A pedagogia ganha uma função política e ocorre uma politização da pedagogia. Para Cambi, os extremos dessa situação foram os totalitarismos do século XX (nazismo, fascismo e socialismo), que investem pesadamente na doutrinação política das crianças, desde a escola.

O estudo da literatura nas escolas tende a se cristalizar em torno dos cânones literários, estabelecidos em grande parte no século XIX. É a época dos grandes autores e das grandes obras que não podem ser contestados e do estudo cronológico da história da literatura. $\mathrm{O}$ biografismo e o historicismo serão a versão positivista do ensino da literatura, opondo-se ao estudo impressionista, que não acredita que o texto literário precise da ciência para ser compreendido. Esse cânone começará a ser questionado no século XX, com as vanguardas e principalmente com a contracultura e a pós-modernidade. O surgimento de novos sujeitos educativos (criança, mulher, deficiente, etnias e minorias culturais) também vai alterar os currículos de literatura das escolas contemporâneas.

A época contemporânea vê ainda surgir os mitos da infância e da educação. Segundo estes, a educação seria a grande solução para os males da sociedade, principalmente se ela fizer parte da vida do ser humano desde a infância. O saber pedagógico torna-se plural e conflituoso provocando reformas sucessivas no sistema educacional, geralmente ao sabor das mudanças no poder político. A escola divide-se entre dois papeis: o de conformação e o de emancipação; ou seja, ao mesmo tempo em que é aparelho de perpetuação do Estado, também pode oferecer possibilidades de libertação aos seus frequentadores.

Esse breve histórico nos mostra como o texto literário passou de documento fundador de uma civilização para um objeto obscuro, cujo valor só é reconhecido por seus leitores. O conceito de Homo faber, que ganhou força sobretudo a partir do século XVII com o surgimento da Ciência Moderna, escanteia paulatinamente tanto a literatura como a filosofia, conhecimentos que haviam estado no auge durante a Antiguidade Clássica e a Idade Média. Em um mundo no qual até mesmo o cinema está ficando obsoleto, não podemos esperar que a literatura faça parte do cotidiano da maior parte de nossos alunos.

\section{Leitura, literatura e os números do Pisa no Brasil}

Enquanto, na Europa Ocidental, a Revolução Francesa foi o marco a partir do qual a educação se massificou, no Brasil, o ponto de partida para uma maior escolarização da população foi a Proclamação da República (1889) (GUIRALDELLI JUNIOR, 2001). Entretanto, mais de um século depois da queda do Império, a educação brasileira ainda está 
longe de apresentar resultados que mostrem pelo menos uma sociedade capaz de ler e escrever, com uma cidadania plena. Uma prova dessa situação calamitosa são os números mais recentes do Pisa, relativos a 2018 e divulgados no ano passado.

Realizado a cada três anos pela Organização para a Cooperação e Desenvolvimento Econômico (OCDE), o Pisa avalia o desempenho de estudantes na faixa dos 15 anos em três domínios (leitura, matemáticas e ciências), sendo que cada edição coloca em foco um desses campos. No Brasil, que participa da avaliação desde sua primeira edição em 2000, a prova é aplicada pelo Instituto Nacional de Estudos e Pesquisas Educacionais (Inep), órgão ligado ao Ministério da Educação (MEC).

Em 2018, o foco do Pisa foi a leitura. De acordo com o Inep (2019), os resultados mostraram que 50\% dos estudantes brasileiros de 15 anos não possuem o nível básico de leitura necessário para exercerem o seu papel como cidadãos, conscientes de seus direitos e deveres. Os maus índices do Brasil estão, por sinal, estagnados desde 2009. Em se tratando de leitura, nosso país ocupa o segundo pior lugar da América do Sul. Apenas 0,2\% dos alunos avaliados atingiram o grau máximo de proficiência em leitura. É imprescindível ressaltar, sobretudo no âmbito deste artigo, que os melhores resultados foram relacionados à leitura de obras de ficção, em texto contínuo ${ }^{3}$, várias vezes por semana (MAGALHÃES, 2020).

Entre as dificuldades enfrentadas pelos estudantes brasileiros está sua incapacidade de compreender um texto. Imaginar que esses alunos não chegam aos bancos da universidade é uma ilusão. Chegam, e essa é uma das principais razões pelas quais a universidade precisa urgentemente repensar sua metodologia de ensino, que geralmente oscila entre a pedagogia tradicional e a pedagogia nova, com suas eternas rodas de conversa, que dificilmente se traduzem em resultados satisfatórios. Em sua maioria, os alunos chegam em sala sem haver lido os textos propostos e a aula não passa de um grande bate-papo, repleto de opiniões pessoais, polarizações político-partidárias e nenhum embasamento científico. Isso sem falar nas provas escritas, que, não raras vezes, revelam a existência de alunos que mal conseguem redigir uma única proposição coerente.

Ora, diante desse cenário, não podemos partir do princípio que os alunos são capazes de acompanhar - e ainda menos de apreciar - nossos cursos magistrais sobre a literatura que tanto amamos. Como vimos no exemplo que dei no começo deste artigo, muitos são incapazes até de compreender o que queremos deles depois da leitura de um texto. Eles não entendem nem

\footnotetext{
${ }^{3}$ Textos contínuos são aqueles formados por frases organizadas em parágrafos, como romances, contos, matérias de jornal, cartas, etc.
} 
mesmo a importância da literatura na formação de um professor de língua materna ou estrangeira, e nem todos os nossos sermões podem convencê-los do contrário. Muitos se voltam para o campo da linguística, afirmando que o fazem por não gostar de literatura, como se os grandes teóricos da linguística não fossem também grandes leitores.

Diante desse quadro, acreditamos que o ensino explícito se mostra capaz de levar o aluno "pela mão", pois trata-se de um procedimento voltado justamente para alunos iniciantes, seja de que disciplina for, e que precisam de um "andaime" para avançar no seu aprendizado. A leitura é uma habilidade cognitiva secundária e necessita, por isso, de motivação e treinamento consideráveis para ser realizada, diferentemente de aprender a falar em língua materna, por exemplo (HAASE et al, 2015).

\section{Algumas palavras sobre o ensino explícito}

O ensino conhecido como explícito tem como base a psicologia cognitiva, que se constituiu nos anos 50 do século passado e coloca em foco o funcionamento do cérebro e sua relação com o ensino e a aprendizagem. Para ela, o aprendizado está relacionado à memória, sendo a mente um sistema de tratamento de informação. O aprendizado seria o conjunto dos processos, permitindo a aquisição de novos conhecimentos ou a transformação dos já existentes. A metacognição, ou seja, a capacidade de refletir sobre o próprio pensamento, tornaria esses processos mentais mais eficazes e estaria na base do ensino explícito.

Os primeiros estudos sobre o ensino eficaz ancorados na psicologia cognitiva datam dos anos 70. Esse tipo de ensino aposta no efeito professor para o desempenho dos alunos, sustentando-se em pesquisas que mostram que o meio familiar e socioeconômico não são fatores decisivos para o sucesso escolar de crianças e adolescentes (GAUTHIER et al, 2018). De acordo com o mesmo autor, o próprio ensino explícito já foi objeto de pesquisas que comprovaram sua eficácia em disciplinas como literatura, matemática, língua materna, ciências, história e línguas estrangeiras. Além disso, o ensino de estratégias metacognitivas, que data dos anos 80 , também já foi alvo de estudos que mostraram sua validez no ensino da compreensão do texto em literatura, por exemplo.

Mas o que vem a ser o ensino explícito? Para começar, é importante ressaltar que ele não exige que o professor altere drasticamente sua prática ou necessita de grandes investimentos por parte da escola. Trata-se de uma abordagem instrucionista de ensino, pois, por meio dela, o professor busca a aprendizagem dos alunos de modo sistemático, estruturado e explícito. $\mathrm{O}$ ensino explícito e outros modelos que se encaixam nessa abordagem preveem basicamente as 
seguintes etapas sequenciadas e integradas para o ensino: 1) Revisão dos aprendizados anteriores para que seja feita a ligação com a matéria do dia; 2) Abordagem, por pequenas etapas, da matéria do dia, com alternância entre apresentações curtas e perguntas; 3) Exercícios dirigidos comfeedback; e 4) Exercícios individuais repetidos até a autonomia do aprendiz. Tal ensino pode ser utilizado não apenas com crianças e adolescentes, mas também com adultos, ajudando tanto alunos com mais dificuldade de aprendizado como os mais avançados, bastando, para isso, a adaptação dos procedimentos ao nível do aluno.

Nesse ponto, é importante traçar as diferenças entre ensino explícito, ensino tradicional e ensino magistral. A tradição pedagógica, que data do século XVII e tem origem na disciplina ascética religiosa, é baseada no controle: de tempo, do espaço, dos saberes, e até da conduta, da postura e dos movimentos. Em contraposição a essa metodologia, surge no século XX a nova pedagogia que, apesar dos avanços que apresenta, acaba se colocando de forma maniqueísta em relação à pedagogia tradicional. Essa demonização do ensino tradicional, que aliás tornou a própria palavra "tradicional" pejorativa, acabou deixando de lado aspectos positivos da tradição, como a gestão da classe, absolutamente necessária para que o trabalho se desenvolva a contento no ambiente escolar. Já a aula magistral, típica do ensino superior, é uma das formas da tradição pedagógica. Trata-se de um monólogo do professor para a transmissão do conteúdo, enquanto os alunos tomam notas.

Embora busque recuperar aspectos que considera positivos da tradição pedagógica, o ensino explícito não se confunde com ela. Da mesma forma, embora critique, não se opõe completamente às propostas de teorias que adotam o paradigma do aprendizado, como o construtivismo. Não se trata, portanto, de escolher entre o ensino explícito e o aprendizado por descoberta, nem tampouco de misturar os dois. De acordo com Gauthier, as evidências mostram que o ensino explícito é mais eficaz em se tratando de alunos iniciantes e com mais dificuldades no aprendizado. No caso de alunos mais avançados, cabe aplicar uma metodologia que lhes permita mais autonomia. Gauthier (2018, p. 1150-1) explica:

Quanto mais iniciantes forem os alunos, maior deve ser o andaime (scaffolding): as tarefas devem então ser simples, baseadas em habilidades específicas e dirigidas pelo professor, e o aluno deve ser guiado em um contexto de problemas simulados. Do mesmo modo, quando um professor trabalha com alunos competentes, estes últimos têm menos necessidade de apoio. As tarefas apresentadas são então complexas e exigem saberes organizados e habilidades integradas. Elas são focadas no aluno, a quem cabe a iniciativa de procurar soluções no contexto de problemas autênticos. 
Não se trata evidentemente de menosprezar alunos, e sim de apresentar as melhores condições para que estes obtenham sucesso em um contexto no qual os seguintes fatores são essenciais: a competência do aprendiz, o tempo disponível e a complexidade da tarefa. Mostrar ao aluno que seu êxito escolar pode depender em grande parte de esforços e estratégias significa corroborar a noção de inteligência dinâmica e proporcionar uma maior motivação para esse aluno. Ao contrário, convencê-lo de que sua performance na escola está limitada por situações que ele não pode controlar, como seu nível socioeconômico, reforça a ideia de uma inteligência estática e, portanto, da inutilidade dos esforços do aprendiz.

\section{Segunda parte}

\section{Narrativa e narrativas}

“Quem conta um conto aumenta um ponto." O conhecido ditado popular parecia, até recentemente, aplicável apenas a nossas relações pessoais. Era uma boa defesa (e ataque) contra fofocas que pudessem parecer bastante diferentes da realidade que lhes dera origem. Mas o alcance e o efeito dessas fofocas cresceram bastante com as redes sociais, agravados pelo anonimato permitido pela internet, e geram hoje uma série dos chamados "cancelamentos" e “assassinatos de reputação".

Em tempos de fofocas via bytes, entretanto, o ditado popular sobreviveu. Ou, pelo menos, sua essência. E com uma vantagem: o usuário de internet, munido de seu smartphone, aprendeu na prática que uma mesma história pode ter várias versões, dependendo de quem a conta. Pode ser até pior que uma mentira: pode ser uma meia-verdade, o que tende a tornar mais difícil sua identificação. Aprendeu ainda que as histórias mal contadas não são privilégio de círculos sociais. Ganharam um nome em inglês - fake news - e podem surgir de fontes, até pouco tempo atrás, consideradas confiáveis, como a imprensa. Eis que, no vocabulário da população, impõese um termo da teoria literária: narrativa.

De acordo com Reis e Lopes (1988, p. 66), a palavra "narrativa" pode ser entendida de várias maneiras: enunciado, conjunto de conteúdos desse enunciado e ato de os relatar. Para os estudos literários, no entanto, eles afirmam que deve prevalecer a definição da "[...] narrativa como modo, termo de uma tríade de "universais" (lírica, narrativa e drama) que, desde a Antiguidade e não sem hesitações e oscilações, tem sido adotada por diversos teorizadores”. Isso porque as outras acepções já possuem termos literários que possam designá-las, como: discurso, história e narração. 
Os autores destacam que a palavra "narrativa" ultrapassa os domínios da teoria literária, como na imprensa e na historiografia. Entretanto, apenas nos últimos anos, temos visto o termo invadir as conversas reais e principalmente virtuais do cidadão dito "comum", geralmente pouco afeito às leituras literárias, como já vimos, e ainda menos aos estudos literários. Nessas conversas, a palavra é quase sempre usada de modo pejorativo: "Essa é a sua narrativa”, diz o oponente, deixando claro que, para ele, o outro está apenas adaptando a realidade às suas conveniências ideológicas. Nesse sentido, vemos aqui recuperada a noção de narrativa como conjunto de conteúdos, história. Vemos ainda a atualização do velho ditado acima citado, "Quem conta um conto aumenta um ponto", ainda que, no caso, não se trate apenas de "aumentar" a história, mas de "transformá-la" a seu bel-prazer.

Ora, ao ressaltar a existência de múltiplas narrativas sobre um mesmo fato, os opositores dessa batalha verbal destacam o papel da origem dessas informações - o "quem" do nosso ditado. Este nada mais é do que o $e u$ da enunciação e sua capacidade de subjetividade. De acordo com Émile Benveniste (2000, p. 259), a subjetividade na linguagem é justamente a capacidade do locutor de se colocar como sujeito da enunciação: "É na e através da linguagem que o homem se constitui como sujeito [...]". A presença do $e u$ pressupõe a existência de um $t u$; esse $t u$, por sua vez, também pode tornar-se um $e u$.

$\mathrm{Na}$ narrativa literária, esse $e u$, esse quem origem da enunciação é predominantemente representado pela categoria do ponto de vista (também conhecido como foco narrativo, perspectiva, etc. $)^{4}$, podendo este ser considerado o locus por excelência da ideologia da obra, conforme afirma Massaud Moisés (1985, p. 408):

[...] o ponto de vista, além de condicionar a avaliação de um romance, articula-se intimamente com o modo como o autor ou/e narrador vê as coisas e o mundo: em grande parte, a cosmovisão de um escritor se manifesta por meio do ponto de vista, sobretudo na medida em que o ângulo visual determina, deforma ou informa, tudo o mais que se contém num texto narrativo. Exprime, assim, não só uma opção estética como também, e notadamente, ética: a obra literária como expressão dos últimos fins do Homem se evidencia na escolha do foco narrativo; conforme sejam vastas ou estreitas as concepções éticas dum autor, assim será o ponto de vista empregado nas suas obras.

Mas esse autor/narrador também está presente nas narrativas do cotidiano. E o cidadão dito "comum", ainda que não seja um grande leitor de literatura e muito menos crítico literário, pode identificar essa instância do criador, percebendo sua função ideológica na escolha e

\footnotetext{
${ }^{4}$ Não podemos evidentemente esquecer a figura do autor, mas este se encontra fora do texto literário e só pode ser apreendido por meio de testemunhos pessoais e/ou especulações. Portanto, essa instância foge do escopo de nosso trabalho.
} 
organização dos conteúdos. O que talvez ele não reconheça é a sua própria identidade como um eu igualmente criador de narrativas. Desconhece até mesmo sua condição de romancista da própria vida, se acreditamos no que diz a escritora espanhola Rosa Montero (2003, p. 5), quando afirma que cada ser humano é o escritor da própria existência, sendo a "narrativa a arte primordial dos humanos":

[...] nós, humanos, somos, acima de tudo, romancistas, autores de um único romance cuja escrita leva toda nossa vida, e na qual nos reservamos o papel de protagonista. É uma escrita, claro, sem texto físico, mas qualquer escritor profissional sabe que se escreve, sobretudo, dentro da cabeça. É um rum-rum criativo que lhe acompanha enquanto você dirige; leva o cachorro para passear; enquanto está na cama, tentando dormir. Escreve-se todo o tempo (tradução nossa) ${ }^{5}$.

Que o ser humano seja um grande contador de histórias provavelmente desde que aprendeu a falar talvez seja uma das razões que fazem do ponto de vista a categoria narrativa mais estudada desde o século XIX (GENETTE, 2007), podendo até ser considerada a mais importante entre elas (MOISÉS, 1985).

\section{Estudos sobre ponto de vista}

A moderna teoria do ponto de vista tem início entre os séculos XIX e XX, mas a discussão sobre modos de narrar é bem mais antiga e remonta às reflexões de Platão e Aristóteles sobre a arte. Ambos se preocuparam em diferenciar as histórias contadas pelo próprio poeta, por um personagem, pelos dois ao mesmo tempo e ainda as histórias que se contavam sozinhas, por meio da ação dos personagens, como no teatro. Essa diferenciação está na base dos conceitos de mimesis e diegesis, elaborados pelos dois pensadores gregos e que chegaram até nós, por meio da diferenciação entre mostrar (showing) e contar (telling) (CHIAPPINI, 1987).

Mas é apenas na virada do século XX que começam a tomar forma os estudos que hoje são conhecidos como a teoria do foco narrativo. Desde então, inúmeros estudiosos se dedicaram ao assunto, garantindo até hoje sua importância nas pesquisas de teoria literária e da narrativa. O contexto que possibilitou a multiplicação desses estudos inclui fatores tão diversos quanto:

[...] a consagração das ideologias como pluralidade [...]; a crise do paradigma positivista, arrastando a desvalorização de critérios objetivos e científicos de análise; os investimentos subjetivos próprios de correntes artísticas como o impressionismo e

\footnotetext{
${ }^{5}$ No original: “[...] los humanos somos, por encima de todo, novelistas, autores de una única novela cuya escritura nos lleva toda la existencia y en la que nos reservamos el papel protagonista. Es una escritura, eso sí, sin texto físico, pero cualquier narrador profesional sabe que se escribe, sobre todo, dentro de la cabeza. Es un runrún creativo que te acompaña mientras conduces, cuando paseas al perro, mientras estás en la cama intentando dormir. Uno escribe todo el rato."
} 
o simbolismo; a formulação, por Einstein, da teoria da relatividade geral, no mesmo ano (1916) em que Ortega y Gasset publicava Verdad y perspectiva; a constituição de disciplinas científicas como a psicologia e a psicanálise [...]; o amadurecimento do cinema [...]; a divulgação de correntes filosóficas como a fenomenologia e o existencialismo (REIS; LOPES, 1988, p. 278-9).

$\mathrm{Na}$ medida em que as teorias se sucedem, podemos observar dois movimentos nesses estudos: um vertical e outro horizontal. $\mathrm{O}$ vertical diz respeito ao reconhecimento das diversas instâncias responsáveis pela construção do foco narrativo (narrador, autor implícito, personagem focal, leitor/espectador, etc.). O horizontal tem a ver com a multiplicação dos tipos de narrador (e, em seguida, também dos tipos de focalização). Pode-se, então, dividir esses teóricos em dois grupos: aqueles que contribuíram expandindo a categoria e os que ajudaram a aprofundá-la. É importante lembrar que essa divisão, além de precária, é apenas didática e que, de modo geral, os estudiosos apresentam contribuições nos dois sentidos. Mas ela pode ajudarnos a compreender melhor o grande número de estudos sobre o assunto ${ }^{6}$.

Henry James inaugura a moderna teoria do foco narrativo de modo vertical, por meio dos prefácios que escreveu para sua própria obra, entre 1906 e 1908, nos quais faz uma reflexão sobre sua produção e a arte narrativa em geral. O escritor norte-americano elabora o conceito de personagem refletor, que assume parte da tarefa antes considerada apenas do narrador: é através de sua consciência que a história é apresentada ao leitor. Ou seja, o escritor apresenta uma outra instância narrativa, ou antes, um tipo de intermediário entre o narrador e a narrativa. Essa foi a solução encontrada para evitar a interferência do autor, bem como a utilização da primeira pessoa em textos extensos (CARVALHO, 1981 ${ }^{7}$ ). Tudo em nome da verossimilhança, como destaca Chiappini (1987, p. 13):

O ideal, para James, e que passa a ser o ideal para muitos teóricos a partir dele, é a presença discreta de um narrador que, por meio do contar e do mostrar equilibrados, possa dar a impressão ao leitor de que a história se conta a si própria, de preferência alojando-se na mente de uma personagem que faça o papel de REFLETOR de suas ideias.

\footnotetext{
${ }^{6}$ Não é objetivo do nosso artigo - nem poderia ser - apresentar uma lista exaustiva das teorias de ponto de vista desenvolvidas desde a virada do século XX. Pela mesma razão, não vamos nos aprofundar nos conceitos elaborados pelos teóricos apresentados. Contentar-nos-emos em apresentar um panorama geral da teoria do foco narrativo nos séculos XX e XXI, fornecendo a evolução de alguns estudos que se relacionam direta ou indiretamente com as teorias adotadas em nossa pesquisa. Por essa razão, ficaram de fora textos importantes tais como "O narrador: considerações sobre a obra de Nikolai Leskov", de Walter Benjamin (1994), e "Narrar ou descrever?”, de Georg Lukács (1965).

${ }^{7}$ Utilizando diversas fontes (originais ou não), Alfredo Leme Coelho de Carvalho (1981) oferece ao leitor um panorama bastante variado das teorias de ponto de vista, que tomamos a liberdade de reproduzir parcialmente neste artigo.
} 
Assim, para James, o assunto de uma obra não seria o que o autor observa, e sim um personagem observando. Ele usou vários termos para designá-lo: centro, registrador, refletor, sujeito consciente ou sensível, percebedor, vaso de consciência, espelho, luz central (CARVALHO, 1981, p. 24). Mas o refletor não podia ser qualquer personagem: ele devia apresentar consciência e sensibilidade. Pode-se verificar certa semelhança entre o refletor de James e o personagem focal de Gérard Genette, como veremos mais adiante. Em 1925, apenas alguns anos depois do Velho Mestre, Boris Tomachevski também falou sobre a possibilidade de apresentar os fatos por meio da mente de um personagem, de modo a fornecer ao texto a singularização necessária, garantindo-lhe o status de obra literária. Afirma Carvalho (1981, p. 34): "O crítico russo aponta como um dos processos possíveis para a consecução desse objetivo a 'refração' dos fatos na mente de um personagem”.

Em 1955, um artigo de Wolfgang Kayser traz outra verticalização importante: ele é um dos estudiosos que chamam a atenção para a diferença entre o autor e o narrador - duas instâncias que costumavam ser confundidas. Ainda diversificando as instâncias da perspectiva, Kayser apresenta o conceito de narrador secundário, existente nas narrativas que ele chama de enquadradas, como no caso dos romances epistolares, em que as cartas são apresentadas por um personagem extradiegético, que assume o papel de narrador, juntamente com os personagens intradiegéticos. Ele destaca também a figura do narratário, ou seja, o leitor ficcional, outra instância que, posteriormente, ganhará importância nas reflexões sobre o ponto de vista, assim como o leitor real (CARVALHO, 1981).

Em 1961, mais um aprofundamento na categoria: Wayne Booth publica A retórica da ficção (The rhetoric of fiction), apresentando o célebre conceito de autor implícito, instância existente entre o autor e o narrador. Para Booth, o autor implícito é “[ [... a imagem implícita de um autor nos bastidores, seja ele diretor de cena, operador de marionetas ou Deus indiferente que lima, silenciosamente, as unhas" (1980, p. 167). Ele explica:

\footnotetext{
O sentido que temos do autor implícito inclui não só os significados que podem ser extraídos, como também o conteúdo emocional ou moral de cada parcela de ação e sofrimento de todos os personagens. Inclui, em poucas palavras, a percepção intuitiva de um todo artístico completo; o principal valor para com o qual este autor implícito se comprometeu, independentemente do partido a que pertence na vida real - isto é, o que a forma total exprime (p. 91).
}

Em 1972, é a vez de Gérard Genette introduzir outra diferenciação vertical, a que separa a narração da focalização, ou seja, quem conta e quem vê a história. Verticalmente, temos, 
portanto, três instâncias de ponto de vista a considerar em uma narrativa: autor implícito, narrador e personagem.

Além de divulgar as ideias de Henry James, em seu livro A técnica da ficção (The craft of fiction, 1921), Percy Lubbock elaborou os famosos conceitos de cena e sumário (CARVALHO, 1981). A cena é o tratamento dramático da narrativa, que utiliza predominantemente o discurso direto e tem a ver com o mostrar (showing). Já o sumário representa o tratamento pictórico, apoiando-se fundamentalmente no discurso indireto e no contar (telling). Pode haver uma mistura de ambos no estilo indireto livre. Apesar de suas ideias dogmáticas (Lubbock preconizava a superioridade do mostrar sobre o $\operatorname{contar}^{8}$ ), a distinção cena/sumário servirá como ponto de partida para classificações posteriores do narrador, contribuindo, assim, para a expansão horizontal do conceito.

Ainda segundo Carvalho, em 1943, no livro Understanding fiction, Cleanth Brooks e R. P. Warren apresentam uma classificação com quatro tipos de narrador: o personagem principal que conta sua própria história, o personagem-observador que participa da história, o autorobservador e o autor onisciente ou analítico (os dois primeiros na primeira pessoa e os dois últimos na terceira). Essa classificação nos lembra o famoso trabalho de Norman Friedman, que veremos logo abaixo. Três anos depois, Jean Pouillon, em seu livro O tempo no romance (Temps et roman), vai introduzir a célebre classificação da visão com, visão por trás e visão de fora - na qual visão é sinônimo de ponto de vista.

Em 1955, Norman Friedman publica o que seria um marco na teoria do ponto de vista: sua classificação do foco narrativo, no conhecido artigo $O$ ponto de vista na ficção (Point of view in fiction). Friedman amplia ainda mais o eixo horizontal, classificando o narrador a partir da distinção entre contar (sumário) e mostrar (cena): onisciência interpretativa, onisciência neutra, eu como testemunha, eu como protagonista, onisciência seletiva múltipla, onisciência seletiva, método dramático e câmera.

Em 1970, Bóris Uspenski publica um livro no qual expande o conceito de ponto de vista. Para ele, pode haver vários tipos de perspectiva narrativa, que ele chama de planos: ideológico, fraseológico, temporal, espacial e psicológico. Geralmente, os autores se dedicam a estudar o plano psicológico (primeira ou terceira pessoa). O ideológico tem a ver com as ideias transmitidas. $\mathrm{O}$ fraseológico, com a transmissão da perspectiva por meio das frases. O plano

\footnotetext{
${ }^{8}$ Suas ideias serão alvo da crítica de Edward Morgan Forster e Edward Muir, respectivamente nas obras Aspectos do romance (Aspects of novel, 1927) e Estrutura do romance (The structure of the novel, 1928). É nessa obra que Forster apresenta o famoso conceito de personagens planas e redondas.
} 
espacial, com a localização do narrador em relação aos personagens (fio condutor da narração). E o plano temporal, com o tempo adotado para a narrativa. A tipologia de Uspenski reforça o fato de que o ponto de vista extrapola a simples questão do relato realizado na primeira ou na terceira pessoa.

Dessa forma, se na posição vertical temos três instâncias de ponto de vista (autor implícito, narrador e personagem), na posição horizontal vemos que o narrador e o personagem podem ser classificados de várias maneiras quanto à perspectiva narrativa adotada. Por essa razão, para analisar o ponto de vista de uma obra, é necessário determinar de qual visão estamos falando e saber que todas elas sintetizam a ótica, que é a perspectiva do autor implícito (DAL FARRA, 1978). O ponto de vista relevante para cada estudo vai depender dos objetivos de cada análise e do corpus da pesquisa.

\section{Ensino explícito, literatura e ponto de vista: uma proposta de aula}

Apresentamos, em seguida, uma proposta de aula baseada na metodologia do ensino explícito. Esta seção apresenta apenas elementos da primeira etapa do modelo PIC do ensino explícito (Preparação - Interação - Consolidação), pois a metodologia ainda não foi por nós aplicada de modo sistemático. O objetivo é a leitura e análise do conto "A casa de Astérion”, de Jorge Luis Borges, e o estudo da categoria narrativa do ponto de vista. Incomodados com os maus resultados obtidos na aula descrita no começo deste artigo, tentamos imaginar como ministraríamos esta aula hoje, utilizando uma metodologia diferente. Tendo em mente as quatro etapas propostas pela abordagem instrucionista, podemos pensar em uma aula com duração de 4 horas - ou seja quatro horas-aula geminadas, como prevê atualmente o sistema de ensino adotado pela UFPB. Eventualmente, é aconselhável fazer um intervalo, cuja duração dependerá das necessidades físicas e mentais de docente e discentes.

1) Revisão dos aprendizados anteriores para que seja feita a ligação com a matéria do dia (30 minutos):

- Esta aula pode ser ministrada em um conjunto de aulas sobre categorias narrativas (ponto de vista, personagem, enredo, tempo, espaço). Seu assunto (ponto de vista) pode ter começado a ser apresentado na aula anterior (nesse caso, esta aula seria um tipo de reforço e prática do conteúdo já ministrado) ou poderá ser apresentado na aula seguinte (o que faria desta aula uma introdução à aula posterior). 
- Em lugar de fazer a revisão (ou introdução) em forma de exposição, o professor pode realizá-la na forma de perguntas informais, que podem ser respondidas pelos alunos, sendo estes eventualmente ajudados pelo professor em caso de dificuldades. Afinal, não se trata de uma avaliação, mas de despertar a memória do aluno para aumentar a sua receptividade à matéria do dia. Esse recurso não é uma novidade para os professores e muitos de nós, como alunos, já pudemos comprovar sua eficácia. É importante também observar que o ensino explícito não exclui a aula expositiva, mas busca apresentar o conteúdo em pequenas etapas, em respeito à memória de trabalho 9 do aprendiz.

2) Abordagem, por pequenas etapas, da matéria do dia, com alternância entre apresentações curtas e perguntas (uma hora e meia):

- Muitos professores, atualmente, tenderiam a apresentar diretamente o conto para a leitura pelos alunos e, em seguida, a perguntar sua interpretação, para evitar "influenciá-los" com "sua visão". No entanto, isso pode criar um bloqueio nos alunos, pois, além da falta do hábito da leitura, estes esbarrariam numa série de dificuldades provocadas pela ausência de conhecimentos prévios, como o mito do Minotauro. Pior ainda seria pedir que o texto fosse lido em casa e que os alunos já chegassem em sala com sua opinião na ponta da língua. Provavelmente, a maioria da turma não o faria ou o faria de modo rápido e insuficiente. De qualquer modo, o texto, que é relativamente curto, será melhor trabalhado se a leitura se der durante a aula ou também durante a aula.

- Antes da leitura, o professor pode apresentar algumas informações introdutórias, como a biografia do autor, o contexto de surgimento da obra, o mito do Minotauro, etc. Mais uma vez, não se trata necessariamente de uma aula magistral, podendo os pequenos momentos de exposição serem intercalados com perguntas, em respeito à memória de trabalho dos alunos. Vários recursos, além da voz do professor e do quadro, podem ser utilizados, como slides e pequenos vídeos ${ }^{10}$.

- Em seguida, será o momento da leitura. Costuma-se começar por uma leitura individual. No entanto, mais uma vez, estamos lidando com alunos iniciantes, sem prática de leitura/leitura

\footnotetext{
9 A memória de trabalho ou memória de curto prazo possui uma capacidade limitada de armazenamento de informações, que costumam permanecer no sistema durante um tempo limitado. A sua sobrecarga faz com que o aluno não consiga processar as informações recebidas e transferi-las para a memória de longo prazo, o que seria necessário para o aprendizado.

${ }^{10}$ As atualmente bastante discutidas metodologias ativas propõem uma série de atividades que podem ser utilizadas pelo professor para apresentar o conteúdo programático, de modo que sua aula não se transforme em um monólogo (CAMARGO; DAROS, 2018). Pretendemos desenvolver esse assunto em um artigo posterior.
} 
literária, que podem ler rápido demais e chegar ao final sem entender nem mesmo linguisticamente o que leram. O melhor é propor a leitura individual por meio de jogos. Por exemplo, cada um pode ler individualmente o texto, mas, ao final, haverá um sorteio para que cada aluno sorteado conte uma parte da história. Como se vê, o ensino explícito não exclui o uso de jogos, tão apreciados pelo construtivismo.

- Em seguida, pode-se e deve-se fazer uma leitura coletiva por etapas. A leitura em voz alta pode e deve ser compartilhada entre o professor e o restante da turma. Durante essa leitura, o primeiro objetivo é explicar gramaticalmente o texto, caso algum aluno sinta dificuldades em relação ao léxico, à sintaxe, etc. Não se trata ainda de fazer a análise literária do ponto de vista. Durante e depois dessa leitura coletiva, a turma pode confirmar ou não a compreensão que teve a respeito da história.

3) Exercícios dirigidos com feedback (duas horas):

- Neste momento, os alunos podem trabalhar com um exercício escrito, para a análise do ponto de vista do texto. Como afirmamos acima, essa teoria pode ter sido apresentada na aula anterior ou o exercício pode ser uma introdução para a aula seguinte. De qualquer modo, é mais eficaz que o aprendiz tenha diante de si um resumo dos principais pontos teóricos dos quais terá necessidade para analisar o texto. Este exercício pode trazer os principais tipos de pontos de vista e pedir ao aluno que ele identifique a perspectiva narrativa adotada pelo autor implícito. Trata-se aqui de uma etapa mais técnica do trabalho do aluno, a partir de elementos fornecidos pela teoria da narrativa. Nesta etapa, os alunos podem trabalhar em dupla ou em grupos maiores. Uma discussão geral, ao final, servirá como "correção".

- Depois da compreensão do texto e da discussão técnica, os alunos deverão estar prontos para analisar o texto a partir de uma visão mais ampla. Uma pergunta que pode ser feita: quais seus sentimentos em relação ao minotauro de Borges? Medo? Raiva? Pena? O Minotauro da mitologia é um monstro assassino que termina sendo morto por um herói, enquanto o minotauro de Borges apresenta um caráter mais complexo, chegando a sofrer com sua solidão. Qual a relação entre o ponto de vista apresentado pela narrativa e a adesão afetiva do leitor ao personagem, caso ela exista? A discussão pode, assim, se ampliar cada vez mais: de que recursos um narrador (literário ou não) dispõe para convencer seu público? É importante aqui lembrar que o objetivo é promover o desenvolvimento do senso crítico do aluno, ou seja, a sua capacidade de processar informações a partir da análise de um mesmo objeto sob várias perspectivas, não de ensiná-lo a ter uma "opinião correta". Neste ponto do trabalho a teoria da 
narrativa pode se relacionar à experiência cotidiana dos aprendizes com o termo narrativa, como ele vem sendo usado nas redes sociais.

4) Exercícios individuais repetidos até a autonomia do aprendiz:

- Neste ponto da aula, a capacidade de trabalho do aluno já deve estar um tanto reduzida, pois sua mente já teve de processar um alto número de informações. Esses exercícios individuais podem ser a análise de outros contos e/ou trechos de romances, repetindo as etapas apresentadas durante a aula. Podem ser realizados em casa ou no início da aula seguinte. Destacamos que, cada vez mais, evitamos enviar deveres de casa, pela pouca autonomia observada nos alunos. Tem sido mais produtivo trabalhar a maior parte do tempo em sala, mesmo que isso signifique uma redução do material apresentado aos alunos. Não adianta exigir dos aprendizes uma certa quantidade de leitura/escrita se esta não se faz de modo satisfatório ou pior, não se faz de modo algum, pois o trabalho não é realizado. Os alunos mais avançados têm sempre a opção de aprofundar suas leituras e realizar exercícios não obrigatórios que sejam mais desafiadores para o seu nível de competência.

\section{Considerações finais}

Neste artigo, buscamos apresentar uma proposta de aula de literatura por meio da metodologia do ensino explícito, por acreditar que o perfil do aluno brasileiro, mesmo aquele de nível superior, exige um maior apoio por parte do professor para um aprendizado mais efetivo. As aulas magistrais, típicas da universidade, e as rodas de conversa não parecem estar dando conta do tipo de aluno que chega aos bancos universitários, com sérias dificuldades de leitura e de escrita, como pudemos observar a partir dos números do Pisa.

Para isso, apresentamos um breve histórico do ensino da literatura e da educação no Ocidente, localizando nessa linha do tempo os estudos de psicologia cognitiva, que fundamentam a teoria do ensino explícito. Também fornecemos alguns números a respeito do nível de leitura do estudante brasileiro e as linhas básicas da metodologia do ensino explícito. Por fim, com o objetivo de embasar a proposta de aula, expusemos as principais teorias literárias sobre o ponto de vista e também o uso da palavra "narrativa" no cotidiano, buscando ampliar as discussões em sala de aula e possibilitar o desenvolvimento do senso crítico do aluno.

Obviamente, este artigo propõe apenas hipóteses de trabalho - como aliás fica claro desde o seu título - a serem desenvolvidas e comprovadas ou não pela prática e por estudos sistemáticos. A profissão de professor certamente não é completamente técnica, mas também 
não pode ser guiada apenas por boas intenções ou achismos, e muito menos por ideologias político-partidárias. Mais do que nunca precisamos de metodologias que sejam capazes de garantir a eficácia do ensino. A não reprovação não é suficiente para manter a autoestima e a motivação dos aprendizes. Afirma Gauthier (2018, p. 2130): "Não adianta fazer tudo para ajudar os alunos a desenvolverem sua imagem de si mesmos [...] se eles não obtiverem êxito no âmbito escolar - os alunos não são bobos, e a imagem pessoal deles sofre com isso". Mais do que nunca, a obrigação do professor é ensinar.

\section{Referências}

BENVENISTE, E. Problèmes de linguistique générale. I. Paris: Gallimard, 2000.

BOOTH, Wayne. A retórica da ficção. Tradução de Maria Teresa H. Guerreiro. Lisboa: Editora Arcádia, 1980.

CAMARGO, F.; DAROS, T. A sala de aula inovadora: estratégias pedagógicas para fomentar o aprendizado ativo. Porto Alegre: Penso, 2018.

CAMBI, F. História da pedagogia. Tradução de Álvaro Lorencini. São Paulo: Fundação Editora da UNESP (FEU), 1999.

CARPEAUX, O. M. História da literatura ocidental. 3. ed. Brasília: Senado Federal, Conselho Editorial, 2008. Volume I.

CARVALHO, Alfredo Leme Coelho de. Foco narrativo e fluxo da consciência: questões de teoria literária. São Paulo: Pioneira, 1981. (Manuais de estudo).

CHIAPPINI, Ligia. O foco narrativo. 3. ed. São Paulo: Editora Ática, 1987.

DAL FARRA, Maria Lúcia. O narrador ensimesmado: o foco narrativo em Vergílio Ferreira. São Paulo: Editora Ática, 1978. (Coleção Ensaios).

GAUTHIER, C. et al. Ensino explícito e desempenho dos alunos: a gestão dos aprendizados. Tradução de Stephania Matousek. Petrópolis, RJ: Vozes, 2018. Coleção Ciências Sociais da Educação. Edição Kindle, versão para PC.

GENETTE, G. Discours du récit: essai de méthode. Éditions du Seuil: Paris, 2007.

GUIRALDELLI JUNIOR, P. História da educação. 2. ed. rev. São Paulo: Cortez, 2001. Coleção Magistério - $2^{\circ}$ Grau, Série Formação do Professor.

HAASE, V. G. et al. Por que o construtivismo não funciona. Disponível em: < http://pepsic.bvsalud.org/pdf/psipesq/v9n1/v9n1a08.pdf>. Acesso em: 03 maio 2020.

INEP. Pisa 2018 revela baixo desempenho escolar em leitura, matemática e ciências no Brasil. Disponível em: <http://portal.inep.gov.br/artigo/- 
/asset_publisher/B4AQV9zFY7Bv/content/pisa-2018-revela-baixo-desempenho-escolar-emleitura-matematica-e-ciencias-no-brasil/21206>. Acesso em: 03 maio 2020.

MAGALHÃES, V. F. O “efeito" de ficção na leitura juvenil. Disponível em:

$<$ https://www.iniciativaeducacao.org/pt/ed-on/ed-on-artigos/o-efeito-de-ficcao-na-leiturajuvenil>. Acesso em: 03 maio 2020.

MOISÉS, Massaud. Dicionário de termos literários. 4. ed. São Paulo: Editora Cultrix, 1985.

MONTERO, R. La loca de la casa. Disponível em:

$<$ http://pdfhumanidades.com/sites/default/files/apuntes/La\%20Loca\%20De\%20La\%20Casa\% 20-\%20Rosa\%20Montero-FREELIBROS.pdf>. Acesso em: 03 maio 2020.

REIS, C.; LOPES, A. C. M. Dicionário de teoria da narrativa. São Paulo: Editora Átiva, 1988. Série Fundamentos.

Recebido em: 03/05/2020

Aceito para publicação em: 02/09/2020 